\title{
STRATEGIC USE AND PERCEPTIONS OF ENGLISH AS A LINGUA FRANCA
}

\author{
Alessia Cogo \\ University of Surrey \\ a.cogo@surrey.ac.uk
}

\begin{abstract}
English as a Lingua Franca is today a thriving and vibrant field of research which has sparked considerable debate but also a wealth of studies in various directions. This paper builds on recent research in this field and focuses on two areas of investigation, namely pragmatic strategies and perceptions of ELF, while placing them within the larger theoretical framework of ELF studies.
\end{abstract}

KEYWORDS: English as a Lingua Franca; pragmatic strategies; idiomaticity; language perceptions.

\section{Introduction}

English as a Lingua Franca (henceforth, ELF) has become a vibrant and expanding field of research, which has also, and probably inevitably, sparked considerable debate concerning various issues: its definition, the area of its investigation and how it relates to other disciplines and linguistic traditions. This paper does not aim to provide an exhaustive exploration of these issues, but, building on recent ELF research, it focuses on two areas of investigation - pragmatics and attitudes - and places them within the larger theoretical framework of ELF studies.

First things first - a definition. ELF can be defined as "the common language of choice, among speakers who come from different linguacultural backgrounds" (Jenkins 2009: 200). Most researchers in this field today also specify that, unlike other lingua francas in the world, ELF communication may include native speakers of English, though the majority of exchanges take place among bilingual users of English. ${ }^{1}$ A wealth of empirical research has already documented how ELF speakers successfully

\footnotetext{
${ }^{1}$ ELF and ENL are different and, consequently, a NS of English is not a NS of ELF. That is, if a NS of English is involved in ELF communication she or he will have to negotiate the communicative norms operating in that context, rather than transposing her or his ENL norms.
} 
use English as a common resource for their own needs and purposes (Seidlhofer et al. 2006). This research covers the areas of lexico-grammar (Breiteneder 2009; Pitzl et al. 2008; Ranta 2009; Seidlhofer 2004), phonology (e.g. Jenkins 2000; Walker 2010), pragmatics (Cogo 2009; Firth 2009; Kaur 2009; Mauranen 2007, 2009; Pitzl 2009; Pullin Stark 2009) and attitudes and identity (Cogo forthcoming; Jenkins 2007). In this paper, I provide a short overview of recent research on the strategic use and perceptions of ELF, then I present some data extracts from these two areas and explore their relevance for future research on ELF communication.

\section{Brief overview of research on the strategic use of ELF}

Over the last few years, research on ELF has been particularly fruitful, and a good part of it has followed Seidlhofer et al.'s (2006: 21) advice for future research "to proceed by way of clearly situated qualitative studies with a strong ethnographic element", by producing various studies (cf. Mauranen and Ranta 2009) concerning different communities of practice. It is precisely the concept of community of practice (Wenger 1998), with its ethnographic element, that best suits the lingua franca contexts, where people from various backgrounds in more or less stable communities engage in communicative practices that shape, construct and define the communities themselves (cf. Ehrenreich 2009). Here, unlike traditional speech communities where an established (native speaker) variety constitutes the reference point for its members, the norms are not preestablished, and they are not exonormatively imposed, but they are negotiated by its users ("mutual engagement") for specific purposes ("joint enterprise") by making use of the members' lingua-cultural resources ("shared repertoire"). The latter element of communities of practice is of fundamental interest in ELF research, as ELF speakers, with their individual socio-cultural background, need to jointly develop and continuously negotiate a repertoire of resources which cannot be taken for granted or assumed a priori.

By contrast, the claim is often made that lack of shared knowledge and sociocultural framing between ELF speakers of different linguistic and cultural backgrounds is likely to lead to misunderstanding and communication difficulties, as participants will rely on the norms of their mother tongue and native culture to interpret meaning. Claims of intercultural misunderstandings such as this one have spurred research into intercultural settings, and in the ELF field, this has also meant researchers have tested the validity of such assumptions in ELF communicative contexts. Empirical research conducted in various ELF settings so far has shown that instances of misunderstandings $^{2}$ are rare (Mauranen 2006; Pitzl 2005), that when they do occur, if relevant to the

\footnotetext{
${ }^{2}$ The term "misunderstanding" is here used in a very general sense, though recognising that research in this field distinguishes between "misunderstanding", "non-understanding" and "lack of understanding" (see Bremer and Simonot 1996).
} 
successful completion of the exchange, they tend not to be ignored but to be tackled and dealt with, and that speakers display a number of strategies at their disposal to negotiate meaning (cf. Cogo and Dewey forthcoming).

The interactional strategic practices that speakers employ to prevent, avert or preempt problems of understanding are all part of that "pro-active work" (Mauranen 2006: 135), which is characteristic of ELF communication. For one, repetition and paraphrase were found to be extensively used by speakers (Cogo 2009; Kaur 2009; Lichtkoppler 2007), both to negotiate understanding and to accommodate differences in communicative practices. As Kaur (2009: 120) maintains, "[i]t is likely that the participants' anticipation of difficulty in understanding, arising from the lingua franca context, gives rise to increased efforts at maintaining shared understanding".

However, misunderstandings are not the only moments where negotiation of meaning takes place. The introduction of new ideas, the use of "new-to-the-group" expressions, or "uncommon" idiomatic phrasing can also initiate moments of meaning-making where speakers are asked to negotiate both their resources and their understanding. Seidlhofer (2009; going back to Widdowson 1990: 109) explores two imperatives involved in pragmatic understanding - the cooperative imperative and territorial imperative. The first one concerns speakers accommodating to each other in order to ensure understanding, while the second one works in the opposite way - speakers highlight differences in order to maintain their distinct identity or to create group membership with other speakers. Seidlhofer explains that the two are not mutually exclusive, rather all speakers, including ELF ones, have to balance the two imperatives, and this is particularly relevant for the use of idiomatic expressions.

Seidlhofer argues that ELF users employ the "open choice principle", whereby speakers co-construct idiomatic expressions in discourse, building them "online" in a bottom-up fashion with the resources available to them, which may result in creative expressions that do not conform to NS idiomatic phrasing. As well as the "open choice" idiomatic building, users may opt for what Sinclair (1991) called "the idiom principle", whereby speakers choose pre-constructed phrases for effective communication and economy of effort. These idiomatic expressions, which are integrated or co-constructed by ELF speakers in discourse, serve the function of "territorial sharing or comity"3 (Seidlhofer 2009: 211), where the speakers' sense of belonging does not remain with pre-constructed patterns of ENL usage, but is negotiated through the linguistic resources available to the community of ELF speakers. As illustrated in the data analysis part of this paper, ELF speakers make use of both the open choice principle, by drawing on and negotiating their multilingual repertoire, and the idiom principle, by using preconstructed idiomatic expressions and adapting them in their own terms.

Because of the "heightened variability" of ELF discourse (Dewey 2009), knowledge of culturally specific expressions cannot be taken for granted but need to be co-

\footnotetext{
${ }^{3}$ Here "comity" is to be interpreted in Aston (1993)'s sense of the term as solidarity and support, "feelings and attitudes, rather than knowledge and ideas" (Aston 1993: 226).
} 
developed and negotiated before being accepted as community resources of the shared repertoire. Research has therefore paid particular attention to ELF speakers' shared repertoire, and explored the situated and strategic interaction which makes use of their multilingual resources (Cogo 2009; Klimpfinger 2009). These studies show how speakers adopt their multilingual resources in different ways and for various purposes. Klimpfinger (2009: 367) investigates how codeswitching constitutes "an integral part of the discourse practices of ELF conversations" and is a frequent communicative strategy in the VOICE corpus, ${ }^{4}$ where it is used in a number of functions - to specify an addressee, to appeal for assistance, to introduce another idea, to signal culture and multilingual identity - and often more then one function playing at the same time. The last two overlapping functions, i.e. introducing an idea and signalling membership, are also displayed in the examples reported in this paper, where the exploration of an idea leads to the deployment of various lingua-cultural resources which, by itself, is a badge of membership to this community of practice.

Moreover, cooperation and involvement in ELF conversation is also evidenced from an interactional pragmatics perspective: speakers employ various interactional tools to ensure the successful development of talk. These are features of simultaneous talk, such as backchannels, overlaps, and utterance completions. These features can be used both cooperatively and competitively, but the findings show that most uses concern the support work carried out by the interactants for various purposes, i.e. to ensure the efficient and successful development of the interaction, to maintain the speakers' alignment and to show involvement in conversation (Cogo and Dewey forthcoming).

However, ELF speakers are likely to display varying levels of competence in English, which can again impinge on the outcome of the encounter, and can lead to questions of pragmatic fluency, and to a more appropriate re-conceptualisation of "fluency" in ELF contexts. With this in mind, House has elaborated the concept of pragmatic fluency as the following:

(1) appropriate use of discourse strategies;

(2) ability to initiate and change topics;

(3) ability to "carry weight" in substantive turns-at-talk;

(4) ability to show appropriate uptaking, and responding behavior, via latching and overlapping;

(5) appropriate rate of speech, types of filled and unfilled pauses, frequency and function of repairs. (Adapted from House 1999: 81; House 2002: 262-263.)

More recently, Hüttner (2009) has attempted a re-conceptualisation of fluency as "dialogic fluency", a collaborative construct where both speakers and listeners (not only speakers) collaborate to ensure understanding. In this view, all the elements listed by

${ }^{4}$ The Vienna Oxford International Corpus of English (see http://www.univie.ac.at/voice). 
House are relevant when dialogically employed in appropriate contexts of use. She argues that fluency in ELF cannot "be compared usefully to native-speaker language use or be measured using only the parameters of psycholinguistic studies" (Hüttner 2009: 275), as norms of turn-taking (such as latchings, overlapping and similar), interactional speed and pausing may differ cross-culturally and may need to be dialogically established in discourse, rather than pre-imposed as fixed pragmatic norms. In Hüttner's reconceptualisation of "fluency", therefore, it is not the individuals speaking quickly or without pausing that are regarded as fluent, but conversationalists who can accommodate to their interlocutors, create a feeling of "one conversation" and take responsibility for making the interaction to work.

As we will see in the data analysis below, ELF provides us with a rich field for investigating such a dialogic nature of fluency in examples of naturally occurring communication, but the idea of fluency is also particularly relevant in the perceptions of ELF speakers' competence expressed by the participants in this study. And this is where I now turn.

\section{Brief overview of research on ELF perceptions}

The very act of participating in a community of practice entails a certain degree of alignment not only in terms of communicative practices, but also for what concerns ideas, values and perceptions. Studies of attitudes and perceptions towards ELF and English as an International Language have been numerous, but the most up-to-date overview of this field of research is Jenkins' monograph English as a Lingua Franca: Attitude and identity (2007). In this study, Jenkins explores attitudes towards ELF in general and ELF accents in particular. The investigation is carried out through both qualitative and quantitative analysis of written texts, spoken interaction, questionnaires and interview data. Firstly, Jenkins highlights and confirms the complexity and ambivalence in attitudes towards NNS varieties in general and ELF in particular, while emphasising the crucial role played by identity. Secondly, the author identifies the role of standard language ideology in the formation of language attitudes, i.e. according to standard language ideology all speakers of English, independently of their sociocultural contexts, are expected to refer to NS norms, and, consequently, new varieties of English (for instance, Indian English, Ghanian English, Singaporean English, etc) are seen as deviations from the norm.

Standard language ideology is found to have a direct influence on attitudes to accent. Jenkins (2007) shows how most participants in her research reveal preference for NS accents, and they also point to correctness as the most important criterion in their judgements. The respondents' preferences and prescriptive responses show a direct link with prevailing standard NS English ideology, especially among linguistics professionals, like teachers, which is also supported by other studies (e.g. Cogo forthcoming) conducted among linguistics students. 
However, there are some signs that things might be slowly changing. Jenkins' findings show that not all NNS accents are dispreferred: some accents are considered aesthetically pleasing and/or more easily intelligible than NS accents. Moreover, research conducted in European multilingual settings, such as Erasmus communities of practice, has shown more favourable and receptive perceptions of ELF, where strategic issues, particularly those of creativity and communicative efficiency, are foregrounded, rather than correctness and NS ideology (cf. Kalocsai 2009; Peckham et al. forthcoming 2010).

\section{ELF strategic use}

The following two extracts are selected to exemplify some of the strategies of ELF communication and they are based on a corpus of naturally-occurring, face-to-face conversations among a small group of colleagues in a higher education institution in Great Britain. ${ }^{5}$ The data was collected in an office shared by the colleagues and comprise a total of about 40 hours, out of which about 10 hours are transcribed. The participants in the conversations are aged between 32 and 55, they speak various L1s, and include both less competent and more competent speakers of English.

In the first extract, Jean (L1 French), Karen (L1 German) and Anna (L1 Italian) are talking about what they have planned for the weekend. Jean says he will not be able to go to Bertha's leaving celebration as he is going to France for a wedding.

(1) The French wedding

$\begin{array}{lll}1 & \text { KAREN: } & \text { have you received the e-mail for Bertha's leave? } \\ 2 & \text { JEAN: } & \text { =yeah } \\ 3 & \text { KAREN: } & \text { =are you going there? } \\ 4 & \text { JEAN: } & \text { =I won't be there } \\ 5 & \text { KAREN: } & \text { why not? } \\ 6 & \text { JEAN: } & \text { = because I'll be in France, } \\ 7 & \text { KAREN: } & \text { a:h } \\ 8 & \text { JEAN: } & \text { for a wedding, } \\ 9 & \text { KAREN: } & \text { a:h [a:h } \\ 10 & \text { JEAN: } & \text { that the weekend ... and I'll stay because ... yeah } \\ 11 & & \text { this Australian is-student is marrying this French } \\ 12 & & \text { girl in Paris and so ... so well organised ... all by } \\ 13 & & \text { interne::t } \\ 14 & & \ldots \\ 15 & \text { KAREN: } & \text { (chuckle) } \\ 16 & \text { JEAN: } & \text { so I have to } \\ 17 & \text { ANNA: } & \text { but it's good? }\end{array}$

${ }^{5}$ For more details about the context and participants, see Cogo (2009). 


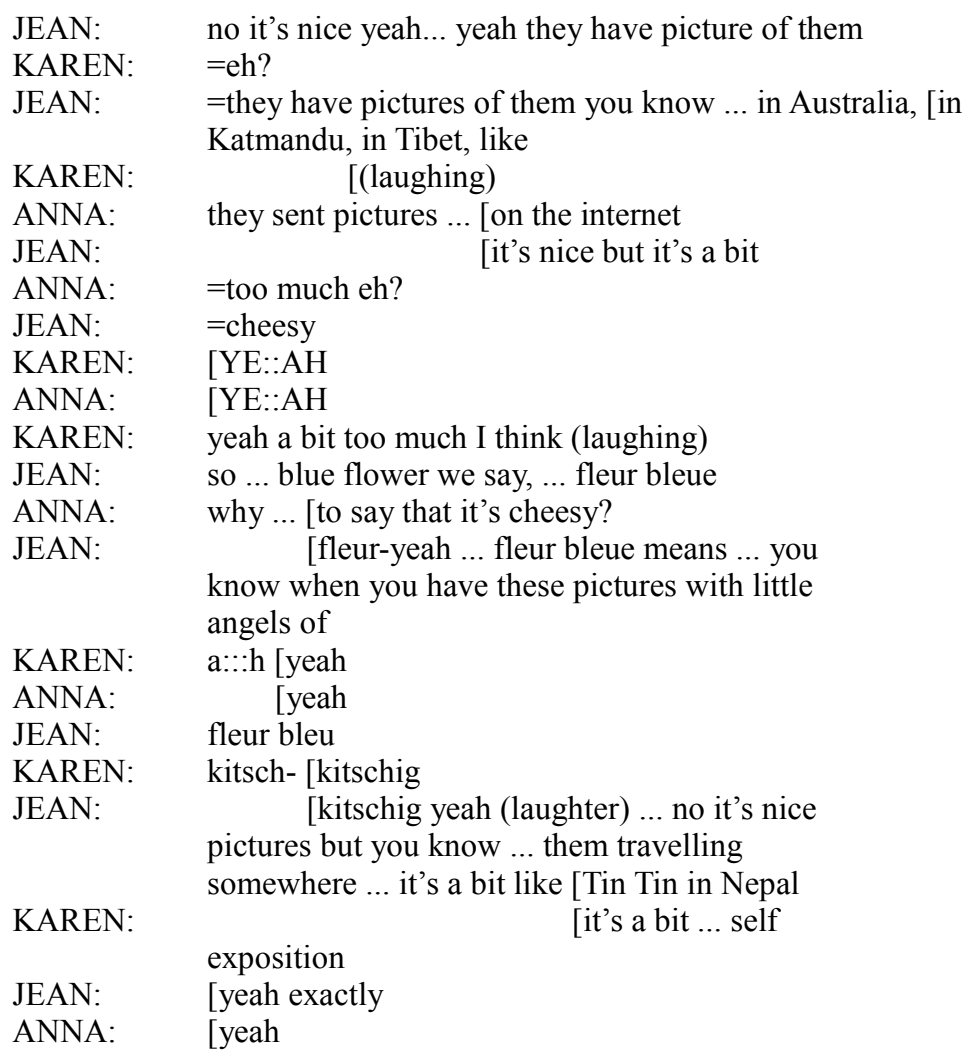

The extract is an interesting example of the kind of negotiation of meaning moments that are characteristics of ELF exchanges. Here the negotiation is started off by the use of the term cheesy (line 26) to describe the website and pictures that the wedding couple had set up (lines 12-21). From the retrospective interviews conducted with Jean, he explains that the term cheesy did not exactly clarify what he wanted to say, i.e. that "the pictures are too much but they are also sweet at the same time". The idiom fleur bleue, instead, provides a much richer meaning than cheesy. It comes from the old-fashioned pictures of angels that used to hang on the wall by children's beds as a symbol of protection. The angels were usually carrying blue flowers, hence the expression fleur bleue.

However, the interesting point about this expression is not so much its use in terms of the surface features that are being employed in this instance, but the process of negotiation that fleur bleue is initiating, and the strategies that the participants adopt to make sense of, elaborate and expand on this expression. To start with, Jean is making an apriori clarification of an idiomatic expression that could have created misunderstanding, and maybe breakdown in the communication. By providing the translation first ("blue flower" in line 30), Jean is not relying on the other participants being familiar with the 
French expression, and, instead, is providing the English translation for them to refer to. But Jean's awareness of possible "unilateral idiomaticity" (Seidlhofer 2009) is just the beginning of the considerable amount of strategic and interactional work he is undertaking. In the same line, Jean immediately follows the English translation by "we say", which provides a gloss to the expression, signaling that it is something used by a certain community of speakers, the "we" Jean is referring to.

As clarified later, by Jean's retrospective comments on this extract, the "we say" in line 30 is a reference to French people, who "say" this expression. Jean also added that he was not sure how widespread the French expression was in France, but that it was used in the area where he is from. In other words, this expression may not be very common among French people and may not be known by the co-participants either, therefore Jean translates it and then frames it (with "we say") so that the other speakers are aware of its potential of being misunderstood and of the need to pay attention to it. Jean's awareness of this expression being culturally sensitive motivates the pre-empting strategies of translation and framing, which are directed to avoid non-understanding, influence the interpretation of what follows and help the co-participants to interpret the idiom and place it into context.

The rest of the extract is also interesting in terms of pragmatic strategies: after the use of the expression in French, Anna starts a negotiation sequence (line 31) by using repetition for clarification and thus enquiring about the meaning of fleur bleue. After that, Jean confirms ("yeah" line 32) that the expression corresponds to cheesy and further explains where it comes from, that is "the pictures of little angels" (lines 33-34). At this point Karen recognizes the idea ("a:::h" line 35) and confirms her understanding at the same time as Anna (overlapping "yeah" line 35-36). From now onwards, Karen engages more actively in the exploration of meaning connected to fleur bleue and provides the German expression kitschig (line 38). The following turn consists of Jean's repetition of kitschig and his acknowledgement of understanding and support for Karen's contribution. For Karen's part, kitschig does not end the expansion of meaning as she further elaborates when she next takes up her turn by saying that it is "self exposition" (line 42-43). This last expression is also endorsed by both interlocutors in a simultaneous overlapping utterance (lines 44-45). Karen's retrospective interview provides support for this interpretation: "I was trying to think of what fleur bleue could be in German", and kitschig was the closest expression she could find. "I also thought selbstdarstellung would be a good expression ... that's where this [self exposition] is from".

The level of engagement and investment in the communication is also evident from an interactional perspective, whereby the French Wedding extract provides an example of the sort of interactional supportive work that is characteristic of the ELF exchanges in this corpus and other corpora of ELF research (see, for example, Mauranen and Ranta 2009). More precisely, the participants use various interactional features such as overlaps, backchannels (such as "yeah"), repetitions and latchings, which, while ensuring the smooth delivery and efficiency of the exchange, also contribute to create a sense 
of "one conversation". Speakers perform interactional work to support the dialogic exchange and make sure that they have achieved mutual understanding. This also highlights the collaborative view of negotiation - speakers and listeners do not simply process meaning independently, but they actively collaborate to ensure understanding.

During the whole conversation, which lasted about ten minutes, the level of engagement and rapport created by the participants in the ways explored above is considerably high, collaboration and group consensus is well established and, within that, the use of participants' various lingua-cultural resources plays a key role. The richness of the exchange, exemplified in the French Wedding snapshot, displays before our eyes the process of negotiating and collaborating in a meaning-making activity, which does not aim to or converge towards ENL idiomatic expressions or linguistic norms, but makes meaning by accepting and building on the participants' contributions, while at the same time creating a sense of comity, solidarity and in-group belonging. What is also clear from the example above is that ELF is not a reduced or simplified code, but a shared repertoire of lingua-cultural resources, which are constantly negotiated through mutual engagement in a community of practice. Meaning and understanding in ELF are therefore not taken for granted, but seen by participants as something to be jointly constructed, negotiated and monitored on a turn-by-turn basis. In this sense, it is not so much a matter of which forms are taken up by ELF speakers and get established as stable variations, but the interest lies in the strategies and processes employed while engaging in meaning making and ensuring intelligible and effective communication.

In the second extract, Isabel (L1 Portuguese), Nana (L1 Japanese) and Anna (L1 Italian) are talking about work relations in their institution and Nana wants to say that all the participants are "in the same boat".

(2) The boat

\begin{tabular}{|c|c|c|}
\hline $\begin{array}{l}1 \\
2\end{array}$ & ISABEL & $\begin{array}{l}\text { I mean we don't have problems ... we all get } \\
\text { on veah }\end{array}$ \\
\hline 4 & NANA & $\begin{array}{l}\text { yeah I think we are all on the same } \ldots \text { on in } \ldots \text { ah: what is it } \\
\ldots \text { on the same boat }\end{array}$ \\
\hline 5 & ISABEL & yeah? \\
\hline 6 & NANA & yeah? ... how do you say? on the same boat? \\
\hline $\begin{array}{l}7 \\
8\end{array}$ & ISABEL & $\begin{array}{l}\text { I don't know yeah ... on the same boat I think ... on the bus } \\
\text { on the train }\end{array}$ \\
\hline 9 & ANNA & anyway we understand you \\
\hline 10 & ISABEL & yeah ... we are all foreigners \\
\hline 11 & NANA & all foreigners (laughing) \\
\hline
\end{tabular}

This extract is an example of an online negotiation of the idiomatic expression to be in the same boat. The expression is introduced by Nana in reaction to Isabel's comment about the working relations inside the community, i.e. that the members get on well, by specifying that they all face the same challenges and needs when working together, in 
other words, they are in the same boat. However, Nana is unsure about the preposition that collocates with the expression, as indicated by the pauses showing hesitation and the use of "on" and "in" sequentially in the same turn (line 3). This is followed by a request for help ("what is it?") and for confirmation of the idiom ("on the same boat?") in line 4. After Nana's request repetition, Isabel does not seem to accept authority on the idiomatic phrasing ("I don't know" in line 7), but she accepts it ("yeah" in line 7) and then starts playing with it, alternating the means of transport that could substitute "the boat" concept, i.e. "the bus" and "the train" (line 8). Isabel cleverly mirrors Nana's prepositional alternation by creating a further lexical alternation and, thus, continues playing with the idiomatic expression. Anna adds that Isabel and herself ("we") understand what Nana wants to say, and Isabel continues to justify the reason why that understanding is taking place - "we are all foreigners" (line 10). It is also significant that Nana follows Isabel's contribution by repeating her justification (line 11), thus showing agreement and positively orientating to Isabel's playfulness.

The participants' "foreignness" is present throughout the short exchange. From the beginning Nana foregrounds her non-nativeness by questioning the preposition and explicitly requesting help to solve the issue. In the retrospective interviewing Nana said she was unsure about what preposition to use in that occasion and she thought Isabel would know, as "Isabel speaks English better than me". When asked about Isabel's reaction, Nana comments positively on Isabel's play with words both during and after the interaction took place. Nana does not seem to be disappointed with Isabel's assertion of not-knowing and her playing with the expression, as she dismisses the importance of strictly adhering to the NS idiom, while creatively changing it and building on its metaphoricity (Pitzl 2009) serves to establish a sense of playfulness and in-group belonging.

The sense of in-group belonging is explicitly signalled by Isabel's use of the pronoun "we" and the adverb "all", which display cohesion, communion and membership in the group of "foreigners", or non-native speakers that can allow themselves to be jokingly creative with forms. However, Isabel's positive orientation to a "shared nonnativeness" (cf. Hülmbauer 2009: 328) is not what initially motivates Nana to enquire about the correct form of the idiomatic expression. On the contrary, and this is also confirmed by the comments she makes after the conversation, Nana assumes Isabel knows better than her, and that she could provide the correct preposition. Nana's orientation, therefore, is more ambiguous and seems to be shifting from an initial appeal to correctness (or what is expected to be the correct preposition) to an acknowledgement that shared foreignness may be fine and understood.

In the following section, I focus precisely on these shifting orientations and the influence of ideological positionings in interview and focus group data.

\section{ELF perceptions}

Focusing on ELF perceptions is necessary to understand to what extent changes in the use of English, and its associated social practices, reflect shifts in attitudes towards ELF 
and ELF communities of speakers. In this sense it is particularly important to explore the attitudes of young people, who may constitute the future players in ELF communities of practice.

The second part of this paper, therefore, concerns a study of ELF perceptions which was conducted among young people in the UK, and served to complement the data collected in another two European settings, the Czech Republic and Hungary. The project consists of interviews and focus groups which involved teenagers at secondary schools and Erasmus students from the three countries. The general aim of the study was to investigate perceptions towards ELF communication and ELF speakers in European contexts, especially the link and tension between communicative effectiveness and native speaker correctness. ${ }^{6}$

In order to do this, interviewees were asked to comment on their experiences of English in international contexts, mainly abroad during school trips or family holidays. The questions concerned "the quality" of the conversations they experienced, such as "How did the conversation go?" and "How was their English?". Participants' comments were usually positive, they would normally include observations on the high level and the good standard, such as the following.

(3) in Belgium I didn't meet one person who didn't [speak English] so .. that was ok ehm quite good actually

Most students said that in their experience of communication with L2 speakers of English their English was usually good. Some of the adjectives used to describe this kind of English were: "immaculate", "good - practically fluent", "incredible" and "impressive". When prompted on what these characterisations of English meant, most people replied emphasising the good communication skills

(4) Just .. their English is really good ... good confidence ... communication skills

Others would specify that good English means speaking it "smoothly", without looking for words and without "hesitations", and a few students underlined the importance of speaking with "confidence":

(5) just high in general - things like using it freely understanding it freely eh ... no hesitation I mean very little hesitation yeah ... quite quite smooth

(6) Just good good confidence like going up to adults asking them .. things and just being able to hold a conversation really and obviously it wasn't perfect like

\footnotetext{
${ }^{6}$ For more details about the data collection settings and methodology employed cf. LINEE (Languages in a Network of European Excellence, www.linee.info), Work Package 7 and 7a, Peckham et al (forthcoming) and Cogo (forthcoming).
} 
they have accents and everything but ehm you still get what they're saying completely and it's not like completely wrong ... or grammatically incorrect that's it

The emphasis on "good confidence", that is on young people being confident enough with their English as to be able to speak with adults and hold a conversation, is not uncommon in the data. What this interviewee adds is that this kind of confidence, though being good, is not entirely correct, not perfect. So, when prompted about "not perfect" the same student said:

(7) obviously it's not perfect English it's not how I would speak or how anyone else's speak that was born and raised here

Unsurprisingly, some interviewees maintained that ELF speakers do not speak English to "perfection", i.e. they do not speak it like people who were brought up "here", i.e. in the UK. This reference to the native speaker ideal is present in every interview and focus group conducted in this study, though sometimes the participants may use other phrasing that covertly underpins a native speaker ideology, without overtly referring to it or to a native speaking country. For instance, in the example below the student, who was on a family trip in Spain, says that Spanish speakers of English have an accent "but apart from that" they are fluent.

they speak good English in Spain .. ehm they got an accent but apart from that they are basically fluent

In this example, though using terms with positive connotations such as "good English" and "basically fluent", the interviewee links his phrasing with a contrastive conjunction such as "but" which is reinforced by "apart from that", indicating that in contrast with the accent the rest of their spoken communication was "basically fluent". Little comments like this one bear on the substantial evaluation of speakers' stances: the common contention is that regional foreign accents are not "allowed" to L2 speakers of English, and that only NSs are "allowed" to have regional accents - in the latter case accents are seen as a sign of identity while in the former they are assumed to be a sign of failure.

Comments on participants' accents are frequent and, while retaining the comparison to NS accents, some students referred to them in different, more positive, terms. In the following comment, for instance, the interviewee links a foreign or NNS accent with positive connotations, such as being "jazzy", "cool", basically "interesting".

$$
\begin{aligned}
& \text { it's jazzy when people have an accent going ... cool ... it's quite interesting if } \\
& \text { you've got an accent }
\end{aligned}
$$

In sum, interviewees' perceptions of ELF communication and speakers are generally positive, with an emphasis on communication skills rather than correctness. However, 
some ambiguity is displayed in their comments concerning accents: interviewees feel that ELF speakers' English is not completely "perfect" because of their foreign accents, though, on the other hand, their accents make them interesting, different from NSs, and give them an edge.

While interview data aimed at investigating individuals' perceptions of ELF communication and communicators without focussing on any particular research direction, but leaving the participants free to articulate their thoughts and opinions about English in the world and in Europe, the focus group data, instead, aimed at discussing the phenomenon of ELF in more details. To this end, the focus group participants were presented with a prompt article on ELF and its implications, which they had to read just before the start of the discussion. ${ }^{7}$

The following extract is taken from the beginning of a focus group discussion among four teenagers in a secondary school in London (UK): they are two Kosovans (Baha and Pise), a Somali (Fara) and a Lebanese (Maje). The students have just finished reading the prompt article, so the following can be seen as their "gut reactions" to it.

(10) The beginning

\begin{tabular}{|c|c|c|}
\hline 1 & Fara & everyone has their own like pattern of speaking \\
\hline 2 & & and when they speak English they put their own \\
\hline 3 & & pattern and you still understand but it's quite \\
\hline 4 & & different \\
\hline 5 & & (4) \\
\hline 6 & Moder. & what did you think in general about it \\
\hline 7 & & (3) \\
\hline 8 & Baha & ehm I've never really thought about it but yeah \\
\hline 9 & & it's so common that you don't really like you see \\
\hline 10 & & it all the time you just never really think \\
\hline 11 & & about it \\
\hline 12 & Fara & you don't notice it \\
\hline 13 & Maje & you don't really notice it cause it's so common \\
\hline 14 & Moder. & where do you .. you say it's common where do \\
\hline 15 & & you see it \\
\hline 16 & Maje & ehm we speak with different people with differ- \\
\hline 17 & & ent countries and we hear their dialects so $[\ldots]$ \\
\hline 18 & & sometimes people they adapt ehm they speak a \\
\hline 19 & & different language they adapt the English lan- \\
\hline 20 & & guage to their grammatical structures or some- \\
\hline 21 & & thing like some languages they put like say the \\
\hline 22 & & verb first before the noun \\
\hline 23 & Pise & yeah \\
\hline
\end{tabular}

\footnotetext{
${ }^{7}$ The prompt article is taken from Jenkins and Seidlhofer (2001). For details on the focus group methodology and settings of the research please refer to Cogo (forthcoming).
} 
The focus group research is quite different from the reactions to general interview questions about English in the world analysed before, where issues of standard language ideology and native speaker correctness underpinned some students' orientations to ELF. Here the participants immediately link ELF with something "different" (line 4), but not deficient, which is related to the participants' lingua-cultural background ("their own pattern" in lines 1-3) and focuses on communicative understanding ("you still understand" in line 4), rather than correctness.

What is strikingly interesting in this extract is the participants' "unsurprised" reaction to the prompt article and the phenomenon it describes - the students all think the phenomenon is "common", it is something you "see all the time" and, at least to their eyes, something "you don't really notice" (lines 8-13). At this point the Moderator ${ }^{8}$ steers the discussion on an elaboration of the common and unnoticed references. Maje explains that the participants are exposed to people from different countries (line 17), who have their own "dialects" and tend to "adapt the English language" (lines 19-20). The choice of words Maje displays in her contribution is quite revealing of a certain sensitivity to variation and linguistic differences: she chooses to use "a different language", instead of "a foreign language", which may have a more alien connotation; and "adapt the English language", instead of "making mistakes". One observation that may be put forward from the analysis of this extract is that the participants' backgrounds, their coming from different socio-cultural contexts and possibly their everyday exposure to cultural and linguistic diversity, may influence their positive orientations towards ELF, as itself born out of language contact and diversity, and displaying similar creativity and meaning negotiation to the ones they are familiar with. Obviously this observation needs to be empirically supported by a larger sample of data, but what can certainly be said so far is that these multilingual and multicultural participants are the ones that seem less "surprised" about ELF.

However, though recognising and accepting linguistic diversity and language variation, the participants seem quite aware of the ideological implications of the adoption of ELF in a European context, as exemplified by Pise's comment below.

(11) Pise: the whole idea when you think of the word English .. the two countries that come to your head are England and America and I think that the kind of the whole of ehm the lingua franca thing is supposed to kind of change that stereotype

Pise is aware of what the word "English" may invoke in people's heads, especially the association of a language with one nation (or two, or more), but she clearly understands that this is, in her own terms, "a stereotype", or, in our own terms, "an ideology". Moreover, she also seems to have understood that uncovering and providing an alternative to this ideology is, partly, what motivated ELF research in the first place.

\footnotetext{
${ }^{8}$ The abbreviation "Moder." in the transcript stands for "Moderator" and is the author of this paper.
} 


\section{Conclusions}

This paper has attempted to give an idea of current research in ELF, basing it on two recent research projects concerning the strategic use and perceptions of ELF. As to the strategic use, speakers show that they can use ELF in their own ways by also drawing on their shared multilingual repertoires. They perform sophisticated strategic behaviour to enhance understanding, create supportive and cooperative communication and display community membership in discourse. Effective interactional work is carried out through various strategies in a supportive manner, so that meaning is explored, clarified and eventually understanding is promoted. In other words, the findings suggest that these speakers are appropriating English for their own purposes, they are signalling their identities through the language and creatively making use of it.

In terms of ELF perceptions, the findings are generally positive: priority is attributed to effective communicative skills, rather than English NS correctness, and ELF speakers were seen as fluent and confident. However, the results also show a certain ambiguity in respondents' comments: on the one hand, they are aware that "good English" and "almost perfect fluency" are themselves value judgement that result from a native speaker ideology, but, on the other, they comment favourably on their foreign accents.

The orientation towards NS fluency as the yardstick against which ELF performance should be measured is still pervasive. The lay perceptions of fluency and competence expressed in this study also refer to an idealised version of individual, native-like, fluency, which is not contextually sensitive. However, on a more positive note, it seems that young multilingual participants are more receptive towards ELF's emphasis on difference rather than deficiency, and its use and negotiation of speakers' shared repertoire and are even starting to look down on NSs of English for their pervasive monolingualism.

This also takes us to a view of ELF which is complementary to studies of bilingualism and multilingualism (cf. for example Auer and Wei 2007; Heller 2007), where this medium of communication is used not instead of other linguistic resources, but works together with those to achieve certain communicative aims. These also involve the construction and negotiation of knowledge, the expansion of meaning, and, last but not least, the purpose of rapport-building and identity construction in contexts of linguistic and cultural diversity.

In conclusion, future research in this field must take into account both the use and perceptions of ELF in specific communities of practice. In this paper, I have provided a brief overview of these areas from two communities of practice constituted by linguistic professionals: the first of language teachers, the second of language students. More indepth ethnographic studies of different communities of practice, both linguists and nonlinguists, are needed to capture both the situated use and the sociolinguistic practices of these communities. Moreover, since scholars have argued the key role that language attitudes play as a basis for intervention in language policy and planning (Giles and Bill- 
ings 2004), it is essential that future recommendations in language policy and language education, especially at the European level, take into considerations the latest developments in this field. Findings from my own research, and others mentioned before, have shown how multilingual Europeans are appropriating English and how language contact among them is leading to language change. This, together with positive perceptions of European ELF and attitudes towards it, makes a strong case for an acknowledgement of ELF in European policy and its effective integration in the multilingual European ecology.

\section{Acknowledgements}

The research reported on this paper was partly supported by the LINEE project, cofunded by the European Commission (contract nr FP6-2004-CIT4-28388), www.linee.info. The author would like to thank Jenny Jenkins and two anonymous reviewers for critical and helpful comments on previous versions of this paper.

\section{TRANSCRIPT CONVENTIONS}

$=\quad$ latching (i.e. speech following the previous turn without a pause)

... $\quad$ short pause (unmeasured)

(0.5) measured pause

[ beginning of overlapping speech

XX unintelligible passage

[...] omitted transcript

\section{REFERENCES}

Aston, G. "Notes on the interlanguage of comity". In: Kasper, G. and S. Blum-Kulka (eds.), Interlanguage pragmatics. Oxford: Oxford University Press. 224-250.

Auer, P. and L. Wei. 2007. "Introduction: Multilingualism as a problem? Monolingualism as a problem?”. In: Auer, P. and L. Wei (eds.), Handbook of multilingualism and multilingual communication. Berlin: Mouton de Gruyter. 1-12.

Breiteneder, A. 2009. "English as a lingua franca in Europe: An empirical perspective". World Englishes 28(2). 256-269.

Bremer, K. and M. Simonot. 1996. "Preventing problems of understanding". In: Bremer, K., C. Roberts, M. Vasseur, M. Simonot and P. Broeder (eds.), Achieving understanding: Discourse in intercultural encounters. London: Longman. 159-180.

Cogo, A. 2008. English as a lingua franca: form follows function. English Today 95. 41-44.

Cogo, A. 2009. "Accommodating difference in ELF conversations: A study of pragmatic strategies”. In: Mauranen, A. and E. Ranta (eds.). 254-273. 
Cogo, A. Forthcoming. “"French is French, English is English': Standard language ideology in ELF debates". In: Studer, P. and I. Werlen (eds).

Cogo, A. and M. Dewey. Forthcoming. Analysing English as a Lingua Franca: A corpus-based investigation. London: Continuum.

Cogo, A. and M. Dewey. 2006. "Efficiency in ELF communication: From pragmatic motives to lexico-grammatical innovation". Nordic Journal English Studies 5(2). 59-93. $<$ http://ojs.ub.gu.se/ojs/index.php/njes/article/view/65/69>

Dewey, M. 2009. "English as a Lingua Franca: Heightened variability and theoretical implications". In: Mauranen, A. and E. Ranta (eds.). 60-83.

Ehrenreich, S. 2009. "English as a Lingua Franca in multinational corporations - Exploring business communities of practice". In: Mauranen, A. and E. Ranta (eds.). 126-151.

Firth, A. 2009. "The lingua franca factor". Intercultural Pragmatics 6. 147-170.

Giles, H. and A. Billings. 2004. "Assessing language attitudes: Speaker evaluation studies”. In: Davies, A. and C. Elder (eds.), The handbook of applied linguistics. Oxford: Blackwell. $187-209$.

Heller, M. 2007. "Bilingualism as ideology and practice". In: Heller, M. (ed.), Bilingualism: A social approach. Basingstoke: Palgrave. 1-22.

House, J. 2002. "Developing pragmatic competence in English as a Lingua Franca". In: Knapp, K. and C. Meierkord (eds.), Lingua franca communication. Frankfurt am Main: Peter Lang. 245-268.

Hülmbauer, C. 2009. “'We don't take the right way. We just take the way that we think you will understand' - The shifting relationship between correctness and effectiveness in ELF". In: Mauranen, A. and E. Ranta (eds.). 323-347.

Hüttner, J. 2009. "Fluent speakers- fluent interactions: On the creation of (co)-fluency in English as a Lingua Franca". In: Mauranen, A. and E. Ranta (eds.). 274-297.

Jenkins, J. 2000. The phonology of English as an international language. Oxford: Oxford University Press.

Jenkins, J. 2007. English as a Lingua Franca: Attitude and identity. Oxford: Oxford University Press.

Jenkins, J. 2009. "English as a Lingua Franca: Interpretations and attitudes". World Englishes 28(2). 200-207.

Jenkins, J. and B. Seidlhofer. 2001. "Bringing Europe's lingua franca into the classroom". Guardian Weekly, 19 April 2001. $<$ http://www.guardian.co.uk/education/2001/apr/19/languages.highereducation1>

Kalocsai, K. 2009. "Erasmus exchange students: A behind-the-scenes view into an ELF community of practice". Apples - Journal of Applied Language Studies 3(1). 24-48.

Kaur, J. 2009. "Pre-empting problems of understanding in English as a Lingua Franca". In: Mauranen, A. and E. Ranta (eds.). 107-123.

Klimpfinger, T. 2009. “'She's mixing the two languages together' - Forms and functions of code-switching in English as a Lingua Franca". In: Mauranen, A. and E. Ranta (eds.). 348371.

LINEE (Languages In a Network of European Excellence). <www.linee.info >

Lichtkoppler, J. 2007. “'Male. Male.' - 'Male?' - 'The sex is male.' The role of repetition in English as a lingua franca conversations". Vienna English Working Papers 16(1). 39-65. $<$ http://www.univie.ac.at/Anglistik/views_0701.pdf $>$

Mauranen, A. 2006. "Signaling and preventing misunderstanding in ELF communication." International Journal of the Sociology of Language 177. 123-150.

Mauranen, A. 2007. "Hybrid voices". In: Fløttum, K. (ed.), Language and discipline perspectives on academic discourse. Newcastle: Cambridge Scholars Press. 243-259. 
Mauranen, A. 2009. "Chunking in ELF: Expressions for managing interaction". Intercultural Pragmatics 6(2). 217-233.

Mauranen, A. and E. Ranta (eds.). 2009. English as a Lingua Franca: Studies and findings. Newcastle: Cambridge Scholars Press.

Peckham, D., K. Kalocsai, E. Kovács and T. Sherman. Forthcoming. "English and multilingualism, or English only in a multilingual Europe?". In: Studer, P. and I. Werlen (eds.).Pitzl, M.L. 2005. "Non-understanding in English as a lingua franca: Examples from a business context." Vienna English Working Papers 14. 50-71.

$<$ http://www.univie.ac.at/Anglistik/Views0502mlp.pdf>

Pitzl, M.-L. 2009. “'We should not wake up any dogs': Idiom and metaphor in ELF”. In: Mauranen, A. and E. Ranta (eds.). 298-322.

Pitzl, M.-L., A. Breiteneder and T. Klimpfinger. 2008. "A world of words: Processes of lexical innovation in VOICE". Vienna English Working Papers 17(2). 21-46.

$<$ http://anglistik.univie.ac.at/fileadmin/user upload/dep anglist/weitere Uploads/Views/ views 0802.pdf>

Pullin Stark, P. 2009. "No joke - This is serious! Power, solidarity and humour in business English as a Lingua Franca (BELF) meetings". In: Mauranen, A. and E. Ranta (eds.).153-177.

Ranta, E. 2009. "Syntactic features in spoken ELF - Learner language or spoken grammar?". In: Mauranen, A. and E. Ranta (eds.). 84-106.

Seidlhofer, B. 2004. "Research perspectives on teaching English as a lingua franca". Annual Review of Applied Linguistics 24. 209-239.

Seidlhofer, B. 2009. "Accommodation and the idiom principle in English as a Lingua Franca". Intercultural Pragmatics 6(2). 195-215.

Seidlhofer, B., A. Breiteneder and M. Pitzl. 2006. "English as a lingua franca in Europe: Challenges for applied linguistics". Annual Review of Applied Linguistics 26. 3-34.

Sinclair, J.M. 1991. Corpus, concordance, collocation. Oxford: Oxford University Press.

Studer, P. and I. Werlen (eds.). Forthcoming. Linguistic diversity in the European Union: First findings of LINEE. Berlin: Mouton de Gruyter.

Walker, R. 2010. Teaching the pronunciation of English as a Lingua Franca. Oxford: Oxford University Press.

Wenger, E. 1998. Communities of practice: Learning, meaning, and identity. Cambridge: Cambridge University Press.

Widdowson, H. 1990. Aspects of language teaching. Oxford: Oxford University Press.

\section{Address correspondence to:}

Alessia Cogo

Department of English

University of Surrey

Guildford

Surrey GU2 7XH

United Kingdom

a.cogo@surrey.ac.uk 